\title{
Sequence of optional tense ${ }^{*}$
}

\author{
M. Ryan Bochnak \\ University of Konstanz
}

\begin{abstract}
In English, sentences containing a past tense in the complement clause of a past-marked propositional attitude predicate (e.g, John said Mary was sick) are compatible with both a simultaneous and a back-shifted reading, in a phenomenon known as Sequence of Tense. In languages like Japanese, only a shifted reading is available for such past-under-past sentences. Two families of theories have been proposed in the literature to account for this variation: structural and pragmatic. Structural accounts rely on a syntactic rule or licensing condition to derive simultaneous readings of embedded clauses. Pragmatic accounts rely on competition between past and present tense in embedded clauses to derive the readings. In this paper, I provide new data from Washo, an optional tense language, to weigh in on the debate on the choice between these theories. In Washo, both tensed and (past-oriented) tenseless embedded clauses can have simultaneous and back-shifted readings. I argue that a structural approach can account for the Washo generalizations fairly straightforwardly, while a pragmatic approach encounters difficulties. The result is that the distribution of simultaneous readings cross-linguistically is more fruitfully viewed as a syntactic phenomenon rather than a pragmatic one.
\end{abstract}

Keywords: tense, embedded tense, sequence of tense, simultaneous readings, optional tense, Washo

\section{Sequence of Tense in complement clauses}

In English, sentences like (1) where a past-tensed clause is embedded under a pasttensed attitude predicate have two readings. On one reading, the time of Mary's being sick overlaps with the time of John's saying, as in (1a). I will refer to this as the

* I would like to thank Washo elders Steven James and the late Ramona Dick for teaching me their language. For comments on this work, I would like to thank Daniel Altshuler, Cleo Condoravdi, Kai von Fintel, Irene Heim, Peter Klecha, Maribel Romero and Hedde Zeijlstra, as well as audiences at the University of Pennsylvania, the University of Konstanz, the University of Göttingen, and SALT 27 at the University of Maryland. Special thanks are due to Vera Hohaus and Anne Mucha. The ideas presented here are expanded in our joint cross-linguistic work (Bochnak, Hohaus \& Mucha 2018). The work reported on here was supported by a grant from the Jacobs Fund of the Whatcom Museum, as well as a Newton International Fellowship funded by the British Academy and the Royal Society, and an Alexander von Humboldt Postdoctoral Fellowship.

(C2017 Bochnak 
Sequence of optional tense

simultaneous reading (SIM). On the second reading, the time of Mary's being sick is in the past of John's saying time, as in (1b). I will refer to this as the back-shifted reading (SHIFT). The availability of the simultaneous reading for past-under-past is often referred to as Sequence of Tense (SoT; e.g., Ross 1967; Ogihara 1989; Heim 1994; Abusch 1997; Stowell 2007, among many others).

(1) John said Mary was sick.
a. John said: "Mary is sick."
simultaneous reading (SIM)
b. John said: "Mary was sick."
back-shifted reading (SHIFT)

It is known that there is cross-linguistic variation in the availability of the simultaneous reading for past-under-past configurations. ${ }^{1}$ For instance, in Japanese, past-under-past morphology yields only the back-shifted reading, as in (2a). To obtain a simultaneous reading, present tense morphology appears in the embedded clause, as in (2b), where the embedded clause is delineated by square brackets. ${ }^{2}$

(2) Japanese:

(Kubota et al. 2009)

a. Ken-wa [Anna-ga byooki dat-ta to] it-ta. Ken-TOP Anna-NOM sick be-past COMPL say-past 'Ken said Anna had been sick.'

SHIFT only
b. Ken-wa [Anna-ga byooki da to] it-ta.
Ken-TOP Anna-NOM sick be.pres COMPL say-past

'Ken said Anna was sick (at the time of saying).'

SIM only

Two families of analyses have been proposed to account for SoT phenomena, which I will refer to as STRUCTURAL and PRAGMATIC approaches. Under a structural approach, two distinct LFs are assigned to past-under-past sentences like (1). The LF corresponding to the SHIFT reading contains two semantically interpretable past tenses, while the LF corresponding to the SIM reading contains no semantic past tense in the embedded clause. The intuition underlying such approaches is that the embedded past tense is semantically not interpreted under the SIM reading, since it does not induce a further backward shift relative to the time of the

1 This paper focuses on past-under-past in propositional attitude complement clauses. Other embedding constructions such as temporal adjunct clauses also give rise to SoT effects, and there is crosslinguistic variation in which embedding constructions trigger SoT effects, and whether SoT effects exist at all. See Ogihara 1989; Arregui \& Kusumoto 1998; Kubota, Lee, Smirnova \& Tonhauser 2009, 2012; von Stechow \& Grønn 2013.

2 Morpheme glosses for non-English examples are as follows: 1, 2, 3 = first, second, third person; COMPL = complementizer; $\mathrm{DEP}=$ dependent mood; IMPF = imperfective; IND = independent mood; LOC = locative; $\mathrm{NMLZ}=$ nominalizer; $\mathrm{NOM}=$ nominative $; \mathrm{O}=$ object; $\mathrm{REFL}=$ reflexive; $\mathrm{REM}=$ remote past; $\mathrm{S}=$ subject; $\mathrm{STATIC}=$ prefix on weather verbs; $\mathrm{TOP}=$ topic 
matrix attitude. The availability of the SIM reading across languages depends on the availability of a syntactic mechanism for deriving what would appear to be a semantics-morphology mismatch. Examples of such accounts in the literature include Ogihara 1995; Kusumoto 1999; Grønn \& von Stechow 2010.

Under pragmatic approaches to SoT, only one syntax/semantics is assigned to sentences like (1), namely one where both instances of the past tense are interpreted. Under such accounts, simultaneous readings for past-under-past do not in fact exist. The appearance of what appears to be a SIM reading for past-under-past in a given language depends on how sentences with past and present tense forms compete pragmatically with one another. Accounts along these lines include Gennari 2003; Altshuler \& Schwarzschild 2012; Altshuler 2016.

In this paper, I bring new data from Washo, an endangered language isolate ${ }^{3}$ spoken in northern California and Nevada, to bear on the correct analysis of SoT phenomena. Washo provides a crucial case for testing the predictions of the structural and pragmatic accounts of SoT because it is an OPTIONAL TENSE language (Jacobsen 1964; Bochnak 2016): finite clauses with past time reference may or may not contain a morphologically overt past tense. I show that past-under-past configurations (i.e., where there is an overt tense in each clause) are compatible with both SIM and SHIFT readings, and argue that a structural account can better handle these facts than a pragmatic one.

The paper proceeds as follows. In section 2 I introduce Washo and my analytical assumptions regarding tensed and tenseless clauses. Section 3 introduces the generalizations on the availability of SIM and SHIFT readings in embedded tensed and tenseless clauses in Washo. In section 4 I introduce structural approaches to SoT phenomena, discuss the predictions for cross-linguistic variation, and show how the analyses can be applied to Washo. Section 5 discusses a pragmatic approach to SIM readings, and I show that such an approach faces difficulty in accounting for the generalizations from Washo. Section 6 concludes, with further comments on cross-linguistic variation in this area.

\section{Optional past tense in Washo}

As was already mentioned, Washo is an optional tense language. Morphologically tenseless clauses such as (3) are compatible with either a present or past interpretation. Such clauses exist alongside those containing the morpheme -unil (allomorph $-y$ uyil), which are restricted to past temporal reference only, see (4).

3 Washo is part of a proposed Hokan family, though this genetic affiliation is controversial; see Campbell 1997; Mithun 1999. 
Sequence of optional tense

$\emptyset$-há?aš-i

3-rain-IND

'It is raining.' / 'It rained.' / 'It was raining.'

\section{$\emptyset$-há?aš-uyil-i}

3-rain-PAST-IND

'It rained.' / 'It was raining.'

In previous work (Bochnak 2016), I argued that -uyil in (4) is the morphological exponent of a semantic past tense, while morphologically tenseless clauses like in (3) are also semantically tenseless. The interested reader is referred to that paper for further arguments and evidence for those claims. It should also be noted that Washo has no dedicated present tense. Present temporal reference is conveyed by morphologically tenseless clauses like (3).

For the purposes of this paper, I assume the following formal implementation of these claims. ${ }^{4}$ I assume a referential analysis of tense, whereby the Reference Time (RT) of the clause is structurally represented as a temporal pronoun (Partee 1973; Heim 1994; Abusch 1997; Kratzer 1998). Like other pronouns, the RT pronoun bears an index and receives its reference from the assignment function $g$. Tense morphology places a restriction on the value of the RT pronoun (variable $i$ in (6c)) relative to an Evaluation Time (EvalT, variable $j$ in (6c); Cable 2013; Bochnak 2016). For the past tense, RT is in the past of EvalT $(i<j)$. I assume (5b) as the structure for the tensed Washo sentence in (5a), and that mood marking in this language is semantically vacuous. ${ }^{5}$ The compositional derivation of this structure is outlined in (6), assuming AspP denotes a predicate of times.

\section{a. ฤ-háPaš-unil-i}

3-rain-PAST-IND

b.

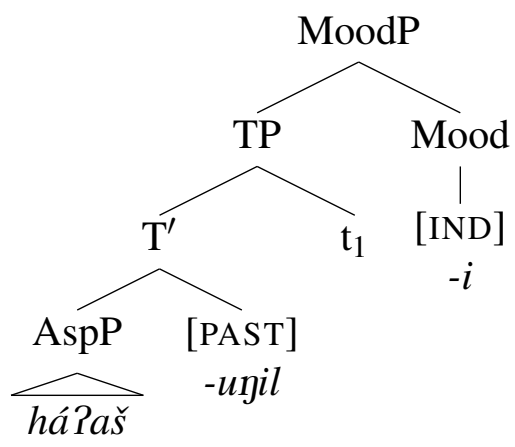

4 In certain details, I depart slightly from the formal details in Bochnak 2016, and adapt the implementation of tense morphology from Klecha 2016. This is done in part to facilitate the comparison with Altshuler \& Schwarzschild's (2012) and Altshuler's (2016) analysis of tense in section 5.

5 See Hanink \& Bochnak 2017 for the view that independent mood $-i$ is vacuous, while dependent mood - $a$ ? instantiates Predicate Modification (Heim \& Kratzer 1998). 
(6)
a. $\llbracket[$ AspP $h a ? a \check{s}] \rrbracket^{g, c}=\lambda t \lambda w \cdot \operatorname{rain}(t)(w)$
b. $\llbracket \mathrm{t}_{1} \rrbracket^{g, c}=g(1)$
c. $\llbracket$-unil $\rrbracket^{g, c}=\llbracket \mathrm{PAST}_{i, j} \rrbracket^{g, c}=\lambda P_{\langle i, s t\rangle} \lambda i \lambda j \lambda w . P(i)(w) \wedge i<j$
d. $\llbracket(5 b) \rrbracket^{g, c}=\lambda j \lambda w \cdot \operatorname{rain}(g(1))(w) \wedge g(1)<j$

By default, the EvalT variable $j$ is identified with the speech time (ST) in matrix contexts, yielding a proposition. Following Cable (2017), I assume that in the absence of a salient past antecedent RT in the context, the RT variable $i$ may be existentially bound, giving (7) in lieu of (6d). This basic architecture is assumed for tensed clauses across languages. ${ }^{6}$

$$
\lambda j \lambda w \cdot \exists i[\operatorname{rain}(i)(w) \wedge i<j]
$$

As for tenseless matrix clauses such as (8a), I assume the structure in (8b). Such clauses still contain an RT pronoun, but there is no tense feature restricting its reference or introducing a relation to EvalT. Although there is no tense restriction on the value of $g(1)$ in (9b)-(9c), RT is in general restricted to non-future times in Washo (see Bochnak 2016 for exceptions to this generalization, as well as Matthewson 2006 and Tonhauser 2011 for non-future temporal reference of morphologically tenseless clauses in St'át'imcets and Paraguayan Guaraní, respectively.)

\section{a. Ø-háPaš-i}

3-rain-IND

b.

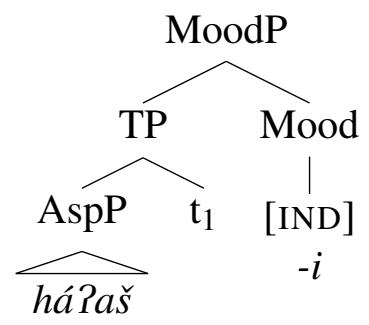

(9)
a. 【[AspP $h a ? a \check{s}] \rrbracket^{g, c}=\lambda t \lambda w \cdot \operatorname{rain}(t)(w)$
b. $\llbracket \mathrm{t}_{1} \rrbracket^{g, c}=g(1)$
c. $\llbracket(8 \mathrm{~b}) \rrbracket^{g, c}=\lambda w \cdot \operatorname{rain}(g(1))(w)$

With this background in place, we can now turn to temporal interpretation of complement clauses in Washo.

6 It has been argued that languages differ with respect to whether tenses should be treated as referential or quantificational. I will set this aside in this paper; see Sharvit 2014 for some recent comments. 
Sequence of optional tense

\section{Sequence of Tense effects in Washo}

Let us now consider the available interpretations for past-under-past configurations, i.e., where there is an overt morphological past tense in both the matrix and embedded clause. As shown in (10), a SHIFT reading is possible: Steven's being sick is located in the past of the matrix event time of saying.

a. Context: Ryan said yesterday: "Steven was sick last week."

b. [Steven $\emptyset$-yáha-yuyil-a?] Ryan P-í:d-uyil-i

Steven 3-be.sick-PAST-DEP Ryan 3-say-PAST-IND

'Ryan said Steven was sick.'

(SHIFT)

As shown in (11), a SIM reading is also available for past-under-past: the time of Reno being big overlaps with the matrix event time of thinking. Thus, a past embedded under past in Washo can receive either a simultaneous or back-shifted reading, just like in English.

(11) a. Context: When you were a child, you thought that Reno was a really big city. But since then, you've visited Sacramento and San Francisco, which are both much bigger, so you now know that Reno isn't that big after all. (context adapted from Cable 2017)

b. [di-mé:hu-ya? lí:nu t'izyeli? k'-é?-uyil-a?] di-hámu-yuyil-i

1-boy-DEP Reno big 3-be-PAST-DEP 1-think-PAST-IND

'When I was a boy, I thought Reno was big.'

= 'When I was a boy, I had the thought: "Reno is big."'

(SIM)

SIM readings can also be expressed using an embedded tenseless clause, either with a tensed or tenseless matrix clause, (12a) and (12b) respectively. Nevertheless, SHIFT readings are also available for those configurations, as shown in (13a) and (13b). The morphological form of the sentences in (12) and (13) is the same, only the contexts are different in order to favor a SIM or SHIFT reading.

(12) Context: You see a man in the street and say "Hi Tim!" He tells you his name isn't Tim. You apologize and say:

a. [Tim de-gum-dí?ye? M-é?-a?] di-hámu-yuyil-i

Tim NMLZ-REFL-name 2-be-DEP 1-think-PAST-IND

'I thought your name was Tim.'

(SIM)

b. [Tim de-gum-dí?ye? M-é?-a?] di-hámu-yi

Tim NMLZ-REFL-name 2-be-DEP 1-think-IND

'I thought your name was Tim.' 
(13) Context: You run into your old friend. His name used to be Tim, but you heard that he changed his name since you last saw him.

a. [Tim de-gum-dí?ye? M-é?-a?] di-hámu-yunil-i

Tim NMLZ-REFL-name 2-be-DEP 1-think-PST-IND

'I thought your name used to be Tim.'

b. [Tim de-gum-dí?ye? M-é?-a?] di-hámu-yi

Tim NMLZ-REFL-name 2-be-DEP 1-think-IND

'I thought your name used to be Tim.'

In the case of an embedded tensed clause with a tenseless matrix clause, only a SHIFT reading is possible, as shown in (14).

(14) [Tim de-gum-dí?ye? M-é?-uyil-a?] di-hámu-yi

Tim NMLZ-REFL-name 2-be-PAST-DEP 1-think-IND

'I thought your name was Tim.'

(SHIFT only)

a. $\checkmark$ Context: You run into your old friend. His name used to be Tim, but you heard that he changed his name since you last saw him.

b. \# Context: You see a man in the street and say "Hi Tim!" He tells you his name isn't Tim. You apologize and say ...

The key generalizations are the following: (i) past-under-past in Washo is compatible with both SIM and SHIFT readings; (ii) the SIM reading can also be expressed using embedded tenseless clauses; and (iii) there is no SIM reading available for an embedded past under matrix tenseless clause. A summary of the interpretations of attitude complement clauses is given in Table 1. These generalizations hold at least for the embedding verbs -hámu 'think' and -íıd 'say'.

\begin{tabular}{|c|c|c|}
\hline & Simultaneous & Back-shifted \\
\hline past-under-past & $\checkmark$ & $\checkmark$ \\
\hline bare-under-past & $\checkmark$ & $\checkmark$ \\
\hline bare-under-bare & $\checkmark$ & $\checkmark$ \\
\hline past-under-bare & $\#$ & $\checkmark$ \\
\hline
\end{tabular}

Table 1 Availability of readings in complement clauses

\section{A structural account for Washo simultaneous readings}

In this section, let us consider how structural approaches to Sequence of Tense could handle the Washo data. The main intuition behind structural accounts is that, in a 
past-under-past configuration, the embedded morphological tense isn't interpreted as such in order to obtain the SIM reading. In other words, for the SIM reading, there no semantic past tense in the embedded clause, whereas for the SHIFT reading, each morphological past tense is semantically interpreted. Different varieties of structural analyses for SoT posit different mechanisms for deriving what appears to be a semantics-morphology mismatch in the case of SIM readings. In this section, I review two varieties of structural approaches - a tense deletion account, and a long-distance licensing account - and consider their predictions with respect to the Washo data. In short: a structural account can handle the Washo facts with minimal additional auxiliary assumptions.

\subsection{Tense deletion}

A classical structural account for SoT phenomena is due to Ogihara $(1989,1995)$ and involves a rule of tense deletion at LF. Under this rule, stated in (15), an embedded tense may be optionally deleted if it is c-commanded by a tense of the same kind. When the rule applies, the embedded past tense is not interpreted, and the temporal variable in the embedded clause is bound by the matrix attitude predicate, yielding a SIM reading; see (16)-(17). In (17), there is only one backward shift: $g(1)$ is in the past of the speech time (ST), and the reference time of the embedded clause is identified with the attitude holder's now, $t^{\prime}{ }^{7}$

\section{(15) Tense deletion rule:}

A tense $\alpha$ may be deleted iff $\alpha$ is c-commanded by a tense morpheme $\beta$, and $\alpha$ and $\beta$ are occurrences of the same tense (adapted from Ogihara 1995)

(16) LF schematic for SIM reading of John said Mary was sick: [PAST John say $[\lambda t$ that PAST(t) Mary be sick ] ]

$$
\begin{aligned}
& \text { Truth conditions for SIM: } \\
& \lambda w \cdot g(1)<\mathrm{ST} \wedge \forall\left\langle w^{\prime}, t^{\prime}\right\rangle \in \operatorname{SAY}(j)(g(1))(w): \operatorname{sick}(m)\left(t^{\prime}\right)\left(w^{\prime}\right)
\end{aligned}
$$

In case the deletion rule does not apply, as it is optional, both past tenses are interpreted, yielding the SHIFT reading, as in (18). Under these truth conditions, there are two backwards shifts: the RT of the matrix clause is in the past of ST, while the embedded RT is in the past of the attitude holder's now. ${ }^{8}$

$$
\begin{aligned}
& \text { Truth conditions for SHIFT: } \\
& \lambda w . g(1)<\mathrm{ST} \wedge \forall\left\langle w^{\prime}, t^{\prime}\right\rangle \in \operatorname{SAY}(j)(g(1))(w): \exists i\left[i<t^{\prime} \wedge \operatorname{sick}(m)(i)\left(w^{\prime}\right)\right]
\end{aligned}
$$

7 The notation SAY is meant to represent the modal component of the attitude verb say and its crosslinguistic counterparts. In $(17), \operatorname{SAY}(j)(g(1))(w)$ denotes the set of world-time pairs compatible with what John says at time $g(1)$ in world $w$.

8 Following Ogihara \& Sharvit (2012), the RT of the embedded clause is existentially bound. 
The optional deletion rule thus creates two distinct LFs with different truth conditions for past-under-past sentences, deriving an ambiguity between SIM and SHIFT readings.

Thinking about cross-linguistic variation under this account, recall that in Japanese, past-under-past allows only a SHIFT reading, and SIM is derived by using an embedded present tense; the data are repeated below in (19).

Japanese:

(Kubota et al. 2009)

a. Ken-wa [Anna-ga byooki dat-ta to] it-ta. Ken-TOP Anna-NOM sick be-past COMPL say-past

'Ken said Anna had been sick.'

SHIFT only

b. Ken-wa [Anna-ga byooki da to] it-ta.

Ken-TOP Anna-NOM sick be.pres COMPL say-past

'Ken said Anna was sick (at the time of saying).'

SIM only

Ogihara proposes that the tense deletion rule in (15) is not available in the grammar of Japanese. Every instance of a morphological past tense must be interpreted, yielding only a SHIFT reading for past-under-past in this language. Variation in the availability of the SIM reading for past-under-past is thus due to parametric variation in the availability of the tense deletion rule in a given language.

\subsection{Long-distance licensing}

More recent structural approaches to SoT views the availability of a SIM reading for past-under-past as a polarity or agreement phenomenon. Under such a view, an embedded morphological past tense can be licensed by or agree with a past tense in the matrix clause (e.g., Grønn \& von Stechow 2010; Kusumoto 1999, 2005; Schlenker 2004; Stowell 2007; Zeijlstra 2012). The semantic past tense operator is divorced from the morphological exponent of past tense; for the rest of this section, I will follow the previous literature in writing PAST for the semantic operator, and past for past tense morphology. The idea is that a morphological past must be licensed by a c-commanding semantic PAST operator.

In a language like English, this licensing may be local or cross clause boundaries. The SHIFT reading is derived as in (20a), where both clauses contain a morphological past that is locally licensed by a semantic PAST within the same clause. Two instances of semantic PAST means two backward shifts, deriving the SHIFT reading. For the SIM reading, the morphological past in the embedded clause is not licensed by a semantic PAST within the same clause, but rather is long-distance licensed by (or agrees with) the semantic PAST in the matrix clause. Under such a configuration, shown in (20b), there is no semantic PAST in the embedded clause, and thus no 
second backward shift, deriving the SIM reading. What is ruled out is a configuration whereby a morphological past is unlicensed by a semantic PAST, an example of which is (20c).
a. SHIFT: [PAST John say-past [ that PAST Mary be-past sick ] ]
b. SIM: [PAST John say-past [ that Mary be-past sick ] ]
c. no: *[ John say-past [ that PAST Mary be(-past) sick ] ]

Cross-linguistic variation is accounted for in the following way. Whereas English allows an LF as in (20b) where an embedded morphological past can be longdistance licensed by (or agree with) a matrix semantic PAST, such LFs are not licit in languages like Japanese (e.g, Kusumoto 1999). In such languages, a morphological past must be licensed by a clause-mate semantic PAST, as in (20a). This means that an embedded morphological past in Japanese always has a corresponding semantic PAST in the same clause, so a complex sentence with two morphological pasts will also contain two semantic PASTs, yielding the SHIFT reading only.

\subsection{Washo under a structural account}

Let us now consider how these sorts of structural accounts can deal with the Washo facts presented in section 3. Recall that the crucial generalizations are that pastunder-past can receive both SHIFT and SIM readings, but that the SIM reading is not available for a past-marked clause embedded under a morphologically tenseless clause; see (21).

\begin{tabular}{|c|c|c|}
\hline & Simultaneous & Back-shifted \\
\hline past-under-past & $\checkmark$ & $\checkmark$ \\
\hline past-under-bare & $\#$ & $\checkmark$ \\
\hline
\end{tabular}

These generalizations can be accounted for under either type of structural account discussed here when we assume that Washo is like English with respect to whatever parameter settings for structural rules deriving SIM (i.e., tense deletion or licensing/agreement of lower morphological past). This will derive the availability of the SIM reading for past-under-past in Washo, since a semantic PAST operator is optionally not present in the embedded clause: either it is optionally deleted by identity with a matrix past as in (15), or Washo allows LFs like (20b) where the embedded morphological past is licensed by or agrees with the matrix semantic PAST.

The absence of the SIM reading for past-under-bare is also predicted by such an account. Since there is no past tense in the matrix clause, the conditions for either the tense deletion rule or long-distance licensing/agreement are not met, and the 
embedded clause must receive a back-shifted interpretation relative to the matrix clause. Note, however, that under a polarity/licensing account, the LF in (22) must be ruled out. Under such a configuration, a semantic PAST in the matrix clause long-distance licenses a morphological past in the embedded clause, without another morphological past in the matrix clause as well. This would derive a SIM reading for past-under-bare.

* [ PAST John say [ that Mary be-past sick ] ]

Such an account requires the auxiliary assumption that a semantic PAST can only long-distance license a morphological past if it also locally licenses a clause-mate morphological past. With this additional assumption in place, both varieties of structural account discussed in this section can handle the facts from Washo.

Let us now turn to pragmatic accounts of SoT and the predictions for optional tense languages.

\section{A pragmatic account for Washo simultaneous readings}

Pragmatic accounts deny that SIM is a distinct reading for past-under-past sentences. They assign these sentences a single syntax-semantics, namely one where both the matrix and embedded tenses are interpreted, deriving only the SHIFT reading (e.g, Gennari 2003; Altshuler \& Schwarzschild 2012; Altshuler 2016). The truth conditions for this reading are repeated in (23).

(23) Truth conditions for SHIFT reading of John said Mary was sick:

$$
\lambda w . g(1)<\mathrm{ST} \wedge \forall\left\langle w^{\prime}, t^{\prime}\right\rangle \in \operatorname{SAY}(j)(g(1))(w): \exists i\left[i<t^{\prime} \wedge \operatorname{sick}(m)(i)\left(w^{\prime}\right)\right]
$$

The main idea behind pragmatic accounts is that under certain conditions, these truth conditions will be compatible with an apparent SIM reading, although no SoT ambiguity is posited at LF or in the truth conditions. Such accounts take it to be crucial that SoT effects typically only surface with embedded stative predicates. ${ }^{9}$

A key ingredient of pragmatic accounts is the view that if a stative predicate holds at an RT interval $t$, then it is also true at a superinterval $t^{\prime}$. This idea is formalized in (24), which says that there is no first or last moment at which statives hold: there always exists some earlier and later moment at which the stative is also true. ${ }^{10}$

\section{Temporal profile of statives (TPS):}

For any tenseless stative clause $\phi$ and moment $m$ : If $\phi(m)=1$, then $\exists m^{\prime}\left[m^{\prime}<m \& \phi\left(m^{\prime}\right)=1\right] \& \exists m^{\prime \prime}\left[m^{\prime \prime}>m \& \phi\left(m^{\prime \prime}\right)=1\right]$

(Altshuler \& Schwarzschild 2012; Altshuler 2016)

9 See von Stechow \& Grønn 2013 for counterexamples in other embedding environments. 10 Since the timeline is dense, this does not entail that statives are temporally unbounded. 
Sequence of optional tense

This has the consequence that in certain contexts, a present tense stative entails a past tense stative: if a stative is true at ST, then there is also a moment in the past of ST where the stative is also true. In contexts where this is the case, a CESSATION IMPLICATURE arises for the use of the past tense. This is because a speaker who uses a past tensed stative should have used a sentence with the stronger present tense if she has reason to believe the latter is true. To see how this plays out, consider (25) from Altshuler \& Schwarzschild (2012). In this context, speaker A sets up the speech time as the topical RT in the discourse. If speaker B is being cooperative, she should respond using the present tense, since the present is topical in the discourse and the truth conditions for the present tense sentence are logically stronger than the corresponding past tense sentence. The truth conditions for B's present tense utterance are given in (26). By TPS, these truth conditions entail those in (27), which are the truth conditions for the past tense version $\mathrm{B}^{\prime}-$ because there is no topical past reference time in the discourse, the RT variable is existentially bound. Since the truth conditions in (27) are weaker than those in (26), B should have used the stronger present tense form if she had reason to believe it is true. Since B did not, she must not believe that the present tense form is true, leading to a cessation implicature. (This reasoning goes through so long as B is knowledgeable about Scotty's state of being at speech time, which can be reasonably assumed given the context provided.)

(25) a. Context: Nurse A asks Doctor B about patient Scotty

b. A: How is Scotty doing?

$\mathrm{B}$ : He is anxious.

$\mathrm{B}^{\prime}$ : He was anxious. $\rightsquigarrow$ cessation implicature: Scotty is no longer anxious

(26) Truth conditions of Scotty is anxious:

$\lambda w \cdot \exists t[t=\mathrm{ST} \wedge \operatorname{anxious}(s)(t)(w)]$

entails (by TPS):

(27) Truth conditions of Scotty was anxious:

$\lambda w . \exists t[t<\mathrm{ST} \wedge \operatorname{anxious}(s)(t)(w)]$

Altshuler \& Schwarzschild (2012) and Altshuler (2016) argue that this reasoning extends to embedded cases as well. It will be instructive to first consider the Japanese cases. Recall that in Japanese, a present-under-past derives the SIM reading. By TPS in (24), the truth conditions for the SIM reading in (28) entail those in (29), which are the truth conditions for past-under-past, i.e., SHIFT.

(28) Japanese present-under-past:

$\lambda w . g(1)<\mathrm{ST} \wedge \forall\left\langle w^{\prime}, t^{\prime}\right\rangle \in \mathrm{SAY}(j)(g(1))(w): \operatorname{sick}(m)\left(t^{\prime}\right)\left(w^{\prime}\right)$

by TPS entails:

(29) Japanese past-under-past:

$\lambda w . g(1)<\mathrm{ST} \wedge \forall\left\langle w^{\prime}, t^{\prime}\right\rangle \in \operatorname{SAY}(j)(g(1))(w): \exists i\left[i<t^{\prime} \wedge \operatorname{sick}(m)(i)\left(w^{\prime}\right)\right]$ 
Now in principle, the SHIFT truth conditions could be compatible with a SIM reading. Since a stative is subject to the superinterval property, it can possibly continue into the future of the past RT and overlap with the attitude holder's now if no outside forces cause it to stop (Gennari 2003). However, this is not possible due to a cessation implicature. Since SIM is strictly stronger than SHIFT, the speaker (in Japanese) should use a present-under-past sentence if she believes that the embedded stative overlaps with the attitude time. Following this reasoning, the use of pastunder-past in Japanese then gives rise to a cessation implicature, and only a SHIFT reading is available for past-under-past.

This type of reasoning does not go through in English. This is because the embedded present in English gives rise to the so-called DOUBLE ACCESS reading (e.g., Smith 1978; Abusch 1997). Under this reading, which is obligatory for English speakers who accept the embedded present tense, the RT for the embedded clause must overlap both the attitude time and the speech time. In (30), the adverb ten years ago is unacceptable, since it would mean that Mary's pregnancy has lasted at least ten years.

John said (\#ten years ago) that Mary is pregnant.

In contexts where the RT given in the discourse does not include the speech time, (30) either comes out false (in the analysis of Altshuler \& Schwarzschild 2012) or has a presupposition failure (in the analysis of Altshuler 2016). As a consequence, a present-under-past sentence is not a suitable competitor for a past-under-past sentence in English, and so it follows that no cessation implicature is derived for past-under-past sentences. This in turn means that a past-under-past sentence in English, which has only SHIFT truth conditions on this view, can in principle be compatible with an apparent SIM reading. Since no cessation implicature arises for past-under-past, the stative in the embedded clause can in principle extend into the future and overlap with the attitude time, if this is compatible with the context, deriving an apparent SIM reading.

In sum, cross-linguistic variation in the availability of a SIM reading for pastunder-past sentences depends on availability of a suitable competitor in a given language to derive a cessation implicature for past-under-past sentences. In Japanese, present-under-past sentences compete with past-under-past sentences - the truth conditions of the former are strictly stronger than the truth conditions of the latter, giving rise to a cessation implicature for past-under-past sentences, and hence no SIM reading. In English, due to the double access reading for the embedded present tense, there is no suitable competitor for past-under-past sentences in order to generate a cessation implicature; therefore, a past-under-past sentence can be used to convey an apparent SIM reading, although no SIM truth conditions are derived for any sentence in English. Essentially, the source of variation lies in the lexical semantics 
of the present tense across languages, namely in whether the present tense is a truly relative tense (Japanese) or contains a deictic component giving rise to double access interpretations (English).

\subsection{Washo under a pragmatic account}

Let us now consider the predictions of a pragmatic account for Washo. Note first that cessation implicatures are reported for the past tense in matrix clauses in Washo (Jacobsen 1964; Bochnak 2016). Jacobsen notes that sentences containing the past tense -uyil very often occur with a follow-up sentence that directly asserts cessation, as in (31). Furthermore, speaker commentary on the elicited example in (32) also indicates the presence of a cessation inference.

t'é:liwhu párti-ya P-é?-unil-i-ya P-íyewe?-i

man party-LOC 3-be-PAST-IND-but 3-go.hence-IND

'The man was at the party, but he left.'

a. Context: I haven't seen Steven for a while, but heard he had been sick, so I ask you how he's been doing lately.

b. Steven (watlí:) git-hámu-Pánaw-unil-i

Steven this.morning 3REFL-feel-good-PAST-IND

'Steven was feeling good (this morning).'

Speaker comment: "Sounds like he got sick again."

However, cessation can be shown to be an implicature, insofar as it can be cancelled, as shown in (33). ${ }^{11}$

a. Context: We're discussing the very hot weather we've been having.

b. bayáya wa-yásay-šému-yuyil-i-na hálaya wa-yásay-šému-yi outside STATIC-hot-really-PAST-IND-but still STATIC-hot-really-IND

'It was hot outside before, and it's still really hot!'

Thus, Washo has English-style cessation implicatures for matrix uses of the past tense, cf. (25). Washo also has an alternative sentence type that entails pastunder-past. Recall that although Washo does not have a dedicated present tense, bare-under-past sentences are also compatible with both SIM and SHIFT readings, just like past-under-past sentences; see (34).

\begin{tabular}{|c|c|c|}
\hline & Simultaneous & Back-shifted \\
\hline past-under-past & $\checkmark$ & $\checkmark$ \\
\hline bare-under-past & $\checkmark$ & $\checkmark$ \\
\hline
\end{tabular}

11 See also Cable 2017 for cessation implicatures in the optional tense language Tlingit. 
Let us assume the truth conditions in (35) for the SIM reading of a bare-underpast Washo sentence. These are the same truth conditions as those for Japanese present-under-past sentences. By TPS in (24), these truth conditions entail the SHIFT truth conditions derived for a Washo past-under-past sentence, as in (36).

(35) Truth conditions for bare-under-past (SIM reading):

$\lambda w \cdot g(1)<\mathrm{ST} \wedge \forall\left\langle w^{\prime}, t^{\prime}\right\rangle \in \operatorname{SAY}(j)(g(1))(w): \operatorname{sick}(m)\left(t^{\prime}\right)\left(w^{\prime}\right)$

(= Japanese present-under-past)

by TPS entails:

(36) Truth conditions for past-under-past (SHIFT reading):

$$
\lambda w . g(1)<\mathrm{ST} \wedge \forall\left\langle w^{\prime}, t^{\prime}\right\rangle \in \operatorname{SAY}(j)(g(1))(w): \exists i\left[i<t^{\prime} \wedge \operatorname{sick}(m)(i)\left(w^{\prime}\right)\right]
$$

Given this setup, a pragmatic account predicts cessation implicatures for Washo past-under-past, parallel with Japanese. Since a form with stronger SIM truth conditions is available, the use of a past-under-past sentence should lead to the implicature that SIM does not hold, predicting that only a SHIFT reading is available for pastunder-past sentences. This in an unwelcome prediction, since a past-under-past sentence in Washo is also compatible with a SIM reading. Note that the absence of a present tense in Washo does not affect the argumentation here. The pragmatic account runs on the entailment relations between sets of truth conditions, and not on the morphological exponence of tense.

It is furthermore unclear how a pragmatic account can deal with the absence of a SIM reading for past-under-bare clauses like (14). If this is due to a cessation implicature derived via competition with an embedded tenseless form, then it remains mysterious why such an explanation cannot be extended to block SIM readings for past-under-past sentences as well.

In sum, a pragmatic account of SoT effects does not make the correct predictions for the availability of SIM readings for past-under-past sentences in Washo.

\section{Conclusion and further cross-linguistic variation}

This paper has offered new insights from Washo as an optional tense language into the debate on the correct analysis of temporal interpretation of complement clauses. I argued that based on the Washo facts, it would seem that a structural approach to SoT phenomena is better able to handle cross-linguistic variation in the availability of SIM readings for past-under-past than a pragmatic approach. The conclusion is that the cross-linguistic (un-)availability of simultaneous readings for past-under-past is better analyzed as a syntactic rather than a pragmatic phenomenon.

Although these conclusions were drawn on the basis of Washo, there is an additional cross-linguistic argument that also favors a structural approach. Namely, 
within the class of optional tense languages, we find variation in the availability of SIM readings for past-under-past. Alongside Washo, Tlingit (Na-Dene) is a language for which SIM readings are available for past-under-past sentences (Cable 2017; see (37)). Meanwhile, Medumba (Grassfields Bantu; Mucha 2017) and Awing (Grassfields Bantu; Mucha \& Fominyam 2017) are optional tense languages where past-under-past only can only have a SHIFT reading (see (38) for Medumba). ${ }^{12}$ In those languages, a tenseless embedded clause is used for the SIM reading.

a. Context: When I was a kid, my uncle would bring over all this really great food to our house. I naturally assumed that he made it, and that he was a really great cook. Turns out, though, that he just bought the food from restaurants downtown!

b. Yéi xwwajéeyin ax káak kúnáx k’idéin

3O.IPFV.1sgS.think.PST my uncle very well

at sa.éeyin

IndefO.IPFV.3S.cook.PST

'I used to think that my uncle cooked really well.' (Tlingit; Cable 2017)

Bú ná' cúb mbə bú ná' búut

they REM say that they REM tired

'The said they were tired.'

(Medumba; Mucha 2017)

a. $\checkmark$ Context (SHIFT): You went to visit Louise and Marie a week ago, right? Did they tell you why they were in such a bad mood two weeks ago?

b. \# Context (SIM): You went to visit Louise and Marie a week ago, right? Did they tell you why they were in such a bad mood that day?

A structural account can straightforwardly explain these patterns as variation in the availability of a tense deletion rule or in the long-distance licensing of an embedded past: Washo and Tlingit have such a rule, whereas Medumba and Awing do not. This sort of parametric variation thus transcends whether tense in a particular language is optional or obligatory. It is less clear, however, how a pragmatic account would handle these facts. As shown in the previous section, such an account predicts that the availability of an embedded tenseless clause that derives the SIM reading should preclude such a reading for past-under-past sentences. Whereas this would appear to be the case for languages like Medumba and Awing, but it is not the case for Washo and Tlingit.

More detailed analyses of individual languages are necessary in order to further test theories of SoT and simultaneous readings and to assess how they account for

12 Medumba is also a graded tense language; the example in (38) contains the remote past ná', but the generalization holds for the near past $f$ a as well; see Mucha 2017 for details, as well as Bochnak, Hohaus \& Mucha (2018) for an analysis of embedded occurrences of optional graded past tenses. 
cross-linguistic variation in this area. In ongoing work, Bochnak, Hohaus \& Mucha (2018) further investigate the availability of simultaneous readings in optional tense languages (Medumba, Washo), graded tense languages (Medumba) and tenseless languages (Hausa, Samoan), and furthermore ask to what extent aspect plays a role in the availability of SIM readings. This is an area that is ripe for further cross-linguistic investigation.

\section{References}

Abusch, Dorit. 1997. Sequence of tense and temporal de re. Linguistics and Philosophy 20(1). 1-50. doi:10.1023/A:1005331423820.

Altshuler, Daniel. 2016. Events, states, and times: An essay on narrative discourse in English. Berlin: De Gruyter Open.

Altshuler, Daniel \& Roger Schwarzschild. 2012. Moment of change, cessation implicatures and simultaneous readings. In Emmanuel Chemla, Vincent Homer \& Grégoire Winterstein (eds.), Sinn und Bedeutung 17, 45-62. Available online at http://semanticsarchive.net/sub2012.

Arregui, Ana \& Kiyomi Kusumoto. 1998. Tense in temporal adjunct clauses. In Devon Strolovitch \& Aaron Lawson (eds.), Semantics and Linguistic Theory (SALT) 8, 1-18. Ithaca, NY: CLC Publications. doi:10.3765/salt.v8i0.2814.

Bochnak, M. Ryan. 2016. Past time reference in a language with optional tense. Linguistics and Philosophy 39. 247-294. doi:10.1007/s10988-016-9191-6.

Bochnak, M. Ryan, Vera Hohaus \& Anne Mucha. 2018. Variation in tense and aspect, and the temporal interpretation of complement clauses. Ms. Universität Konstanz, Universität Tübingen and Institut für Deutsche Sprache, Mannheim.

Cable, Seth. 2013. Beyond the past, present, and future: Towards the semantics of 'graded tense' in Gĩkũyũ. Natural Language Semantics 21. 219-276. doi:10.1007/s11050-012-9092-3.

Cable, Seth. 2017. The implicatures of optional past tense in Tlingit and the implications for 'discontinuous past'. Natural Language and Linguistic Theory 35(3). 635-681. doi:10.1007/s11049-016-9355-7.

Campbell, Lyle. 1997. American Indian languages: The historical linguistics of Native America. New York: Oxford University Press.

Gennari, Silvia. 2003. Tense meanings and temporal interpretation. Journal of Semantics 20. 35-71. doi:10.1093/jos/20.1.35.

Grønn, Atle \& Arnim von Stechow. 2010. Complement tense in contrast: The SOT parameter in Russian and English. Oslo Studies in Language 2. 109-153. Available online at https://www.journals.uio.no/index.php/osla/issue/view/5.

Hanink, Emily \& M. Ryan Bochnak. 2017. Factivity and two types of embedded 
Sequence of optional tense

clauses in Washo. In Andrew Lamont \& Katerina Tetzloff (eds.), North-east linguistic society (nels) 47, vol. Vol. 2, 65-78. Amherst, MA: GLSA.

Heim, Irene. 1994. Comments on Abusch's theory of tense. In Hans Kamp (ed.), Ellipsis, tense, and questions, 143-170. Amsterdam: University of Amsterdam.

Heim, Irene \& Angelika Kratzer. 1998. Semantics in Generative Grammar. Blackwell.

Jacobsen, William H. 1964. A grammar of the Washo language: University of California, Berkeley dissertation. Available online at http://escholarship.org/uc/item/52c6q7hg.

Klecha, Peter. 2016. Modality and embedded temporal operators. Semantics and Pragmatics Article 9. 1-55. doi:10.3765/sp.9.9.

Kratzer, Angelika. 1998. More structural analogies between pronouns and tenses. In Semantics and Linguistic Theory (SALT) 8, Ithaca, NY: CLC Publications. doi:10.3765/salt.v8i0.2808.

Kubota, Yusuke, Jungmee Lee, Anastasia Smirnova \& Judith Tonhauser. 2009. On the cross-linguistic interpretation of embedded tenses. In Arndt Riester \& Torgrim Solstad (eds.), Sinn und Bedeutung 13, 307-320. Stuttgart.

Kubota, Yusuke, Jungmee Lee, Anastasia Smirnova \& Judith Tonhauser. 2012. Cross-linguistic variation in temporal adjunct clauses. In Cahiers Chronos: Selected Proceedings of Chronos 8, 141-161. Amsterdam: Rodopi.

Kusumoto, Kiyomi. 1999. Tense in embedded contexts. Amherst, MA: University of Massachusetts, Amherst dissertation.

Kusumoto, Kiyomi. 2005. On the quantification over times in natural language. Natural Language Semantics 13. 317-357. doi:10.1007/s11050-005-4537-6.

Matthewson, Lisa. 2006. Temporal semantics in a superficially tenseless language. Linguistics and Philosophy 29. 673-713. doi:10.1007/s10988-006-9010-6.

Mithun, Marianne. 1999. The Languages of Native North America. New York: Cambridge University Press.

Mucha, Anne. 2017. Past interpretation and graded tense in Medumba. Natural Language Semantics 25(1). 1-52. doi:10.1007/s11050-016-9128-1.

Mucha, Anne \& Henry Fominyam. 2017. (un-)restricting tense in Awing. In Vera Hohaus \& Wanda Rothe (eds.), Semantics of African, Asian and Austronesian Languages 3, 32-46. Universität Tübingen.

Ogihara, Toshiyuki. 1989. Temporal reference in English and Japanese. Austin: University of Texas dissertation.

Ogihara, Toshiyuki. 1995. The semantics of tense in embedded clauses. Linguistic Inquiry 26(4). 663-679.

Ogihara, Toshiyuki \& Yael Sharvit. 2012. Embedded tenses. In Robert Binnick (ed.), The Oxford Handbook of Tense and Aspect, 638-668. Oxford: Oxford University Press. 
Partee, Barbara. 1973. Some structural analogies between tenses and pronouns in English. Journal of Philosophy 70(18). 601-609. doi:10.2307/2025024.

Ross, John R. 1967. Constraints on variables in syntax. Cambridge, MA: Massachusetts Institute of Technology dissertation.

Schlenker, Philippe. 2004. Sequence phenomena and double access readings generalized. In Jacqueline Guéron \& Jacqueline Lecarme (eds.), The syntax of time, Cambridge, MA: MIT Press.

Sharvit, Yael. 2014. On the universal principles of tense embedding: The lesson from before. Journal of Semantics 31. 263-313. doi:10.1093/jos/ffs024.

Smith, Carlota. 1978. The syntax and interpretation of temporal expressions in English. Linguistics and Philosophy 2(1). 43-99.

von Stechow, Arnim \& Atle Grønn. 2013. Tense in adjuncts part 2: Temporal adverbial clauses. Language and Linguistic Compass 7. 311-327.

Stowell, Tim. 2007. The syntactic expression of tense. Lingua 117. 437-463. doi:10.1016/j.lingua.2005.08.003.

Tonhauser, Judith. 2011. Temporal reference in Paraguayan Guaraní, a tenseless language. Linguistics and Philosophy 34(3). 257-303. doi:10.1007/s10988-0119097-2.

Zeijlstra, Hedde. 2012. There is only one way to agree. The Linguistic Review 29. 491-533. doi:10.1515/tlr-2012-0017.

M. Ryan Bochnak

Fachbereich Sprachwissenschaft

Universität Konstanz

D-78457 Kontanz

Germany

ryan.bochnak@gmail.com 